\title{
Introduction to the Special Issue of the MetroArchaeo 2016 Conference
}

\author{
Sabrina Grassini ${ }^{1}$, Alfonso Santoriello ${ }^{2}$ \\ ${ }^{1}$ Department of Applied Science and Technology, Politecnico di Torino, Torino, Italy \\ ${ }^{2}$ Dipartimento di Scienze del Patrimonio Culturale, Università di Salerno, Italy
}

\begin{abstract}
Section: EDITORIAL
Citation: Sabrina Grassini, Alfonso Santoriello, Introduction to the Special Issue of the MetroArchaeo 2016 Conference, Acta IMEKO, vol. 6, no. 3, article 1, September 2017, identifier: IMEKO-ACTA-06 (2017)-03-01
\end{abstract}

Section Editor: Paul Regtien, Measurement Science Consultancy, The Netherlands

Received September 19, 2017; In final form September 19, 2017; Published September 2017

Copyright: ( 2017 IMEKO. This is an open-access article distributed under the terms of the Creative Commons Attribution 3.0 License, which permits unrestricted use, distribution, and reproduction in any medium, provided the original author and source are credited

Corresponding author: Sabrina Grassini, e-mail: sabrina.grassini@polito.it

Dear Readers,

this special issue of Acta IMEKO contains 14 papers presented at the IMEKO TC4 International Conference on Metrology for Archaeology and Cultural Heritage MetroArchaeo2016, which took place on October, 19-21 2016 in Torino (Italy). The conference was held at the Valentino Castle, an historical building inscribed in the UNESCO World Heritage List in 1997, which actually hosts the Faculty of Architecture of Politecnico di Torino University.

Started in 2015 in Benevento (Italy), MetroArchaeo is becoming a successful international annual meeting, which puts together Heritage scientists, engineers, conservators and archaeologists to foster exchanges of ideas and information on metrology and measurements for Archaeology and Cultural Heritage.

Heritage scientists, engineers, conservators and archaeologists have common interests and understanding in many areas, but at differing levels. Conservators and archaeologists have less understanding of experimental science and measurement, but more experience and pragmatic understanding of heritage assets and their context, practicality and ethics. Heritage scientists and engineers with high expertise in metrology, have greater understanding of interpretation and validation of data, taking into account their reliability and uncertainty.

Today it appears more and more clear that multidisciplinary approaches coupled with appropriate measured survey and imaging data are fundamental requirements for the effective preservation, management and understanding of our cultural heritage, offering also new scenarios for territorial growth from the social-economic point of view.

MetroArchaeo gives all these actors of the scientific and humanistic world the opportunity to discuss and exchange knowledge and to develop integrated systems able to provide answers to historiographical questions and face real problems in research, protection, monitoring and exploitation of cultural heritage and archaeological sites.

More than a hundred papers were presented in Torino and after a careful peer review fourteen papers were eventually accepted for this ACTA IMEKO Special Issue. These papers give an interesting overview of the integrated analytical and measurement approaches in cultural heritage and archaeology and well represents the worldwide attendance to the Conference.

The paper presented by Calicchia et. al., illustrates a new model of a territorial system, the Cultural Heritage Open Laboratory System (CHeLabS), based on open access policy to the cultural assets grounded on the territory and on the technological and social economic context, with the final aim of attracting competencies and generating excellence in heritage science.

Two papers emphasize the contributions of $3 \mathrm{D}$ approaches and digital techniques for the restoration and measurements of cultural heritage artefacts. Stamatopoulos et. al. illustrate a new digital approach for reassembling ancient ceramic pottery based 
on 3D models of their fragments and the exploitation of their thickness profile, with particular attention to the accuracy of the thickness measurements. Dondi et. al. present a new protocol and a 3D model suitable for acquiring precise measurements on historical violins applied to the Stradivari "Cremonese" (1715) kept in "Museo del Violino", Cremona (Italy).

The papers of Lo Brutto et. al. and A. Kubicka highlight the potentialities of digital photogrammetry and laser scanning techniques for the full-scale 3D modelling and representation of archaeological artefacts and sites. A. Angelini et. al. discuss a new algorithm for the $2 \mathrm{D}$ representation and surface reconstruction of heritage buildings. $2 \mathrm{D}$ and $3 \mathrm{D}$ reconstructions are important tools for the documentation and the restoration of cultural heritage, as well as the development of tailored wireless sensors networks, such as the one proposed by L. D'Alvia et. al., are fundamental instruments for the long time preservation of multimateric artefacts displayed in museums.

Five papers are focused on the application of different advanced analytical techniques for the characterisation of inks, ceramics, glasses, stones and metallic artefacts. $\mathrm{THz}$ spectroscopy is proposed by Taschin et. al. to study the absorption coefficient and the reflective index of different inks in form of thin films. R. Pitonzo and co-authors use gas chromatography coupled with mass spectroscopy for the analysis of archaeological ceramic amphorae belonging to the Carthaginian period. The MCX beamline at Elettra is employed by Plaisier et. al. for non destructive X-ray diffraction measurements on stained glasses. The application of ion microbeam analysis in the cultural heritage field is discussed by Lo Giudice et. al., while R. Chapoulie work is focused on photons and electrons for the study of drawings on prehistoric wall caves.

Eventually, two papers by E. Shaykhutdinova discuss interdisciplinary studies on silver coins and iron casting technologies.

We hope that this special issue gives the reader new points of view in metrology and measurement applied to cultural heritage, taking also into account their fundamental role in our society. The special issue wants to highlight the importance of the synergy among all heritage scientists and actors and among the different disciplines, which provides important tools for the monitoring, preservation, management and safeguard of cultural heritage assets.

Hope you will have an interesting reading! Sabrina and Alfonso 